\title{
Quantitative Trait Locus Mapping of Salt Tolerance and Identification of Salt-Tolerant Genes in Brassica napus L
}

\begin{abstract}
Lina Lang ${ }^{\dagger}$, Aixia $\mathrm{Xu}^{\dagger}$, Juan Ding, Yan Zhang, Na Zhao, Zhengshu Tian, Yaping Liu, Yang Wang, Xia Liu, Fenghao Liang, Bingbing Zhang, Mengfan Qin, Jazira Dalelhan and Zhen Huang *
\end{abstract}

State Key Laboratory of Crop Stress Biology for Arid Areas, College of Agronomy, Northwest A\&F University, Yangling, China study, a genetic linkage map based on 532 molecular markers covering $1341.1 \mathrm{cM}$ was constructed to identify the loci associated with salt tolerance in Brassica napus. Up to 45 quantitative trait loci (QTLs) for 10 indicators were identified in the $F_{2: 3}$ populations. These QTLs can account for 4.80-51.14\% of the phenotypic variation. A major QTL, qSPAD5 on LG5 associated with chlorophyll can be detected in three replicates. Two intron polymorphic (IP) markers in this QTL region were developed successfully to narrow down the QTL location to a region of $390 \mathrm{~kb}$. A salt tolerance related gene Bra003640 was primary identified as the candidate gene in this region. The full length of the candidate gene was 1,063 bp containing three exons and two introns in $B$. napus $L$. The open reading frame (ORF) is $867 \mathrm{bp}$ and encodes 287 amino acids. Three amino acid differences $(34,54$, and 83 ) in the conserved domain (B-box) were identified. RT-qPCR analysis showed that the gene expression had significant difference between the two parents. The study laid great foundation for salt tolerance related gene mapping and cloning in B. napus $L$.

Keywords: salt tolerance, QTLs, candidate genes, cloning, expression, Brassica napus

\section{INTRODUCTION}

Soil salinization is one of the crises the world is facing today. Salty soil is a low-yield soil which is widely distributed in the world. It is reported that approximately 37 million hectares of land is exposed to the salinity and secondary salinization in China (Zhang et al., 2007). In recent years, a large number of rapeseed acreage has been reduced rapidly in China's Yangtze River Basin because of low profit, which aggravated the gap of China's edible oil (Yin et al., 2009). Making full use of the saline-alkali soil and planting rapeseed in the saline-alkali soil is one of the most effective ways to alleviate the gap of edible oil in China (Ma et al., 2001). However, the prerequisite for this approach is to cultivate salt-tolerant rapeseed varieties.

Salt tolerance of rapeseed is a quantitative trait, and its phenotype is difficult to be determined under the normal condition. Many complex mechanisms are involved at different plant developmental levels. Salt tolerance in plants is a developmentally regulated phenomenon and the tolerance at one growth stage sometimes may not correlate with that of other stages (Kumar et al., 2015), which has brought difficulties for the genetic research of salt tolerance. For one stage of 
plant growth, researchers often use some physiological and morphological indicators to indirectly determine salt tolerance. The effect of salt stress on plant growth is the result of mineral deficit, ion toxicity, and osmotic stress (Munns, 2002). When the plant is subjected to salt stress for a long time, the growth of the plant is slow, the membrane permeability is increased, and the photosynthesis is blocked (Wang et al., 2006; Zheng et al., 2010; Guo et al., 2013; Li and Zhang, 2013). In rapeseed, the seedling height, root length, aboveground fresh weight, dry weight, underground dry weight, and fresh weight are significantly reduced under salt stress (Wani et al., 2013). Salt stress also affects the physiological indexes of plants. Under salt stress, the content of $\mathrm{K}^{+}$and $\mathrm{Ca}^{2+}$ in rapeseed seedlings decreases significantly, while the content of $\mathrm{Na}^{+}$and $\mathrm{Cl}^{-}$increases significantly, the growth of plants is inhibited, and $\mathrm{Ca}^{2+} / \mathrm{Na}^{+}$and $\mathrm{K}^{+} / \mathrm{Na}^{+}$ decrease with the increase of salt concentration (Peng et al., 2004). When the plant is under salt stress, a large amount of active oxygen is generated, unbalancing the active oxygen metabolism and leading to changes in the activities of peroxidase (POD), catalase (CAT) and superoxide dismutase (SOD). These indexes in plant tissues are closely related to plant stress resistance (Zhang, 2012; Du et al., 2013; Wani et al., 2013). A similar phenomenon was also observed in chloroplasts, which is sensitive to salt stress. When the plants are subjected to salt stress, the chloroplast structure is destroyed, the chlorophyll content is reduced, photosynthesis is weakened and the growth is inhibited (Yang et al., 2010; Zhang, 2012). When salt stress is applied, plants also resist to salt damage by accumulating osmotic protection substances, such as betaine, proline, soluble sugar, and soluble protein, which are the main osmotic regulators in plants (Thakur and Sharma, 2005). Therefore, the growth characteristic of plants is a comprehensive response to salt stress (Kaya et al., 2002).

The complexity of most mechanisms involved in salt stress tolerance limits the development of modern salt tolerance breeding approaches (Yeo and Flowers, 1986). The association and application of the trait (s) of interest such as salt stress toleranceis a well-known approach for the betterment of crops (Im et al., 2014; Kumar et al., 2015). In order to study the mechanism of salt tolerance, researchers used the genetic, and molecular biology methods to map or clone the salt tolerance related genes. Currently, a few salt stress related QTLs detected by simple sequence repeat (SSR) markers have been identified, and these studies are mainly concentrated in wheat (Gorham et al., 1990; Dubcovsky et al., 1996; Lindsay et al., 2004; Huang et al., 2006), rice (Yao et al., 2005; Sabouri and Sabouri, 2008; Ahmadi and Fotokian, 2011) and so on. These QTLs are mainly focused on the $\mathrm{Na}^{+} / \mathrm{K}^{+}$ratio in the root, the content of $\mathrm{Na}^{+}$, the root length, and root dry weight. In Arabidopsis thaliana, some QTLs and salt related genes have also been identified, such as

\footnotetext{
Abbreviations: AFLP, Amplified Fragment Length Polymorphism; CIM, Composite interval mapping; CTAB, Cetyl trimethyl ammonium bromide; EC, Electrical conductivity; IP, Intron polymorphic; LFW, Leaf fresh weight; LGs, Linkage groups; LDW, Leaf dry weight; LOD, Log likelihood of the odds; ORF, Open reading frame; QTLs, Quantitative trait loci; RDW, Root dry weight; RL, Root length; SH, Seedling height; SOD, Superoxide dismutase; SP, Soluble protein; SPAD, Soil and Plant Analyzer Development; STR, Salt tolerance rating.
}

$R A S 1$, a gene encoding a plant-specific expression protein which is involved in plant salt tolerance at germination and seedling stages (Ren et al., 2010); AtPirin1 was cloned in Arabidopsis, which can reduce the seed germination rate, and inhibit seedling growth under salt stress (Nguyen et al., 2007). There are also some studies on salt tolerance in the Brassica species, which were focused on the evaluation of salt tolerance (Jain et al., 1990; Su et al., 2013), salt tolerance homolog gene cloning and expression (Chakraborty et al., 2012). However, few studies on genetics and gene mapping of salt tolerance in $B$. napus were reported. $B$. napus is the main oilseed species in the world because of its considerable economic and nutritional value. The seed germination in $B$. napus is sensitive to salt stress and their growth and oil production are markedly reduced by salinity. Thus, it is imperative to study the salt tolerance in B. napus, cultivate the salt tolerance varieties, enlarge the planting area, so as to increase the amount of rapeseed and alleviate the edible oil gap.

In the previous study, many salt-tolerant breeding lines have been identified in our lab. For example, B. napus line 2205 derived from the restorer line (Z716C) of a B. napus cultivar "Shanyou0913," was discovered through the salt treatment experiment (Huang et al., 2010), which shows a good correlation between salt tolerance and some morphological and physiological indexes. A further study shows this salt-tolerant line can still grow well under high salt concentration (Ding et al., 2014). Therefore, this line has been used as the source of salt tolerance in B. napus. The purpose of this study is to identify the QTLs related to salt tolerance, isolate the salt tolerance related genes in the QTL regions, and analyze the structure and expression of the candidate genes. In addition, hopefully to develop new salt tolerance related markers for marker assisted selection (MAS) of salt tolerance.

\section{MATERIALS AND METHODS}

\section{Plant Materials and Stress Treatments}

An $\mathrm{F}_{2}$ population including 196 individuals derived from two B. napus lines, 2205 (salt-tolerant) and 1423 (salt-sensitive) was constructed for QTL mapping. Each individual of $F_{2}$ was selfed to generate $196 \mathrm{~F}_{2: 3}$ lines, which were used to measure morphological and physiological indexes. Ten plants of each $\mathrm{F}_{2: 3}$ line were measured per replicate. A total of three replicates were assessed, first two replicates were conducted outdoors in the spring of 2013 and 2014 , respectively $\left(15-25^{\circ} \mathrm{C}\right)$, and the third one was cultivated in a light incubator in $2015\left(16 / 8 \mathrm{~h}, 25 / 20^{\circ} \mathrm{C}\right)$. Hydroponic growth was used to cultivate the two parents, $\mathrm{F}_{1}$ and $\mathrm{F}_{2: 3}$ populations, in brief, the seeds of them were first disinfected with $70 \%$ alcohol, soaked in distilled water for $12 \mathrm{~h}$, and then placed in a glass dish to germinate for $48 \mathrm{~h}$ under dark conditions. When the buds were $5-7 \mathrm{~cm}$, the plants were transferred to $1 / 2$ Hoagland nutrient solution ( $\mathrm{pH}$ 6.0), until three leaves appeared, the plants were treated with $200 \mathrm{mM} \mathrm{NaCl}$ for 10 days. In addition, the two parents 2,205 and 1423 were also treated with 0,100 , and $200 \mathrm{mM} \mathrm{NaCl}$ at three leaves time, respectively. The roots and leaves of the two parents were sampled at $0,6,12$, and $24 \mathrm{~h}$, respectively. The samples were stored at $-80^{\circ} \mathrm{C}$ for RNA extraction. 


\section{Evaluation of Morphological and Physiological Indexes}

After 10 days of the salt treatment, 10 morphological and physiological indexes were determined, including root length (RL), leaf fresh weight (LFW), leaf dry weight (LDW), root dry weight (RDW), electrical conductivity (EC), superoxide dismutase (SOD), soluble protein (SP), chlorophyll content (SPAD), salt tolerance rating (STR), and seedling height (SH). A total of 10 individuals from each $\mathrm{F}_{2: 3}$ line were measured, and the average was calculated as the measured value of each index. EC was determined by the method of $\mathrm{Li}$ (2000); SOD was measured by the method of Beauchamp and Fridovich (1971); SP was determined by the Coomassie Brilliant Blue method described by Li (2000) and the chlorophyll content was measured on a SPAD502 plus (Konica Minolta, Japan) following the manufacturer's instructions.

\section{Extraction of DNA, SSR, and Amplified Fragment Length Polymorphism (AFLP) Technology}

Genomic DNA was extracted from the young leaves of $F_{2}$ individuals at the seedling stage by the cetyl trimethyl ammonium bromide (CTAB) method (Doyle and Doyle, 1990). The final DNA concentration was adjusted to $50 \mathrm{ng} / \mu \mathrm{l}$. Sequences of all SSR markers were obtained from public sources: including the Databases on http://ukcrop.net/perl/ace/search/BrassicaDB (Lowe et al., 2004) and http://www.brassica.info/resource/ markers.php (for those with the prefixes: $\mathrm{Ra}, \mathrm{Na}, \mathrm{BN}$, and BRMS-), the electronic supplementary material of Piquemal et al. (2005) (for those primer pairs with the prefixes "BRAS" and "CB"), and the other ones were from the studies of Cheng et al. (2009) and Xu et al. (2010) (for those with the prefixes "Bra," "Bro," and "Brn"). The PCR products were detected by silver staining (Lu et al., 2001). The AFLP method was described by Vos et al. (1995), and the sequences of the pre-amplified primers and selective amplified primers were from Huang et al. (2007).

\section{Genetic Linkage Map Construction and QTL Analysis}

An AFLP and SSR linkage map was established using the MAPMAKER 3.0 program (Lander et al., 1987; Lincoln et al., 1992). A minimum log likelihood of the odds (LOD) score of 3.0 and a maximum distance of $25 \mathrm{cM}$ were used to group loci into linkage groups (LGs). Map distances were calculated using the Kosambi's mapping function (1944). The QTLs were mapped using the composite interval mapping (CIM) function of the Win QTL Cartographer v.2.5 (Basten et al., 1997). The LOD thresholds of QTL were determined by a 1,000 permutation test at a 95\% confidence level. The QTL mapping was performed followed the method of (Fan et al., 2010).

\section{Fine Mapping of the Candidate Genes}

The QTLs detected in all three replicates were selected. The products of the two closest markers around the QTL were sequenced. The collinearity between the sequences of the two markers and the A genome was compared using the BLAST tool (http://brassicadb.org/brad). After the physical position of the QTL on the A genome was determined, the genes within the QTL region were randomly selected for designing intron polymorphism (IP) primers. The detailed method can be referred to Huang et al. (2016). All IP primers were used to amplify the parents and $\mathrm{F}_{2}$ population. WinQTLcart2.5 was used to analyze phenotypes and polymorphic bands.

\section{Total RNA Extraction and cDNA Synthesis}

A RNA prep Pure Plant Kit (TIAN GEN, Beijing, China) was used for total RNA extraction from the root and leaf tissues of the two parents' seedlings that were ground in liquid nitrogen after being processed for $0,6,12$, and $24 \mathrm{~h}$ with 0,100 , and $200 \mathrm{mM}$ $\mathrm{NaCl}$. After DNA removal by DNaseI digestion, agarose gel (mass-to-volume ratio was 1.2\%) electrophoresis was performed to measure RNA concentration and integrity. cDNA synthesis was performed following the instructions of the TIAN GEN FastQuant RT Kit (Beijing, China). These cDNAs were used for analyses of candidate gene cloning and expression.

\section{Amplification of the Candidate Genes}

After the candidate genes were selected in the QTL region, the RT-qPCR technique was applied to amplify the fulllength ORF of the CDNA from the leaf tissues of the two parents' seedlings. The primer sequences were: Forward, 5'-ATGAAGATTCAGTGTAACGTCTGCGAGA-3'; Reverse, $5^{\prime}$-TTAGAACCGTCTTCGCTTCCCAACCCTCT-3'. The fulllength DNA sequence was amplified using the genomic DNA as a template, and the amplification reaction was as follows: denaturation at $95^{\circ} \mathrm{C}$ for $10 \mathrm{~s}$, followed by renaturation at $55^{\circ} \mathrm{C}$ for $5 \mathrm{~s}$, and elongation at $72^{\circ} \mathrm{C}$ for $1 \mathrm{~min}$ for a total of 35 cycles. The Prime STAR Taq DNA polymerase (Takara) was added once the PCR program was suspended. PCR products were purified by a TIAN gel Midi Purification Kit (TIAN GEN, Beijing, China). The purified products were connected to the carrier of the pMD19-T vector, and transformed to Escherichia coli DH5a cells. A total of 10 positive clones were sent to Shanghai Sangon Biological Engineering Technology \& Service Co., Ltd for sequencing. Full-length cDNA sequences were analyzed by the DNAMAN5.0 software. Multiple sequence alignment of the amino acid sequences was performed using the Clustal W. Phylogenetic tree was constructed by the ML (maximum likelihood) method with bootstrap analysis (1,000 replicates) from alignment of protein sequences of candidate genes in Arabidopsis, B. rapa, B. napus, and B. oleracea using MEGA5.0 program. The conserved domains, homologs and physicochemical properties of amino acids were analyzed by SMART (http://smart.embl-heidelberg.de/), Blast (http://blast. ncbi.nlm.nih.gov/Blast.cgi) and PROTPARAM (http://web. expasy. org/cgi-bin/protparam), respectively.

\section{Expression of the Candidate Genes}

RT-qPCR was used to analyze the expression of the candidate genes in the root tissues and leaf tissues from the two parents' seedlings. The SYBR Green Supermix kit purchased from Takara was used for PCR reactions, and the reaction conditions were as follows: pre-denaturation at $95^{\circ} \mathrm{C}$ for 
$2.5 \mathrm{~min}$, followed by denaturation at $95^{\circ} \mathrm{C}$ for $10 \mathrm{~s}$, and renaturation at $60^{\circ} \mathrm{C}$ for $34 \mathrm{~s}$ for a total of 40 cycles; at the end of the reaction, the system was kept at $95^{\circ} \mathrm{C}$ for $15 \mathrm{~s}$, followed by lowering the temperature to $60^{\circ} \mathrm{C}$ for $1 \mathrm{~min}$. The replicates were carried out for each experiment following the manufacturer's instructions. The forward primer sequence was $5^{\prime}$-GAAGCATTTCTCAGTGGCAA-3', and the reverse primer sequence was $5^{\prime}$-ATGATGTCTCACCTCCTCCC- $3^{\prime}$. $\beta$-actin was used as an internal reference, with a forward primer sequence of $5^{\prime}$-TCAAGAAGGCTATCAAGGAG- $3^{\prime}$ and the reverse primer sequence of $5^{\prime}$-GTAACCCCATTCGTTGTCAT- $3^{\prime}$.

\section{RESULTS}

\section{Phenotypic Variation}

The phenotypic distribution of traits related to salt tolerance in the two parents and $196 \mathrm{~F}_{2: 3}$ families are shown in Figure 1. There were differences in all traits between the two parents under $200 \mathrm{mM} \mathrm{NaCl}$ (Table 1). STR and EC of the salt-resistant parent 2205 were higher than those of the salt-sensitive parent 1423 , whereas the other traits of 2205 were lower than those of 1423. There were continuous frequency distribution and transgressive segregation in these indicators among $\mathrm{F}_{2: 3}$ populations under salt stress (Figure 1). The normality test of the observed data in the $\mathrm{F}_{2: 3}$ lines showed that the skewness and kurtosis were not significant (Table 1), indicating a normal distribution of all studied traits.

\section{Correlation of All Indicators}

As shown in Table 2, there were significantly negative correlations among STR, SPAD, and RDW; a significantly positive correlation was found between STR and EC. SPAD was also significantly positively correlated with SP. EC was significantly negatively correlated with RL, RDW, and SFW. RL was significantly negatively correlated with SDW and SFW. SH was only significantly positively correlated with SDW. SP was significantly correlated with SPAD. SOD was only significantly negatively correlated with RDW. SDW was also significantly positively correlated with RDW and SFW. RDW was significantly positively or negatively correlated with STR, EC, SOD, and SDW.

\section{Construction of the Genetic Linkage Map}

A total of 1,800 pairs of SSR and 64 pairs of AFLP primers were used to screen the two parents, 2205 and 1423. Among these, 426 pairs of SSR and 15 pairs of AFLP primers showed polymorphism between the two parental lines, with 24 and 23\%, respectively. These polymorphic primers were then used to screen the $\mathrm{F}_{2}$ population, from which 531SSR polymorphic and 30 AFLP loci were identified. And a total of 502 SSR and 30 AFLP markers were grouped into 19 linkage groups with an LOD threshold of 3.0. The map spanned $1341.1 \mathrm{cM}$ with an average marker interval of $2.52 \mathrm{cM}$. The markers were distributed relatively evenly, with the longest linkage group (LG1) containing 34 markers spanning $110.85 \mathrm{cM}$ and the shortest (LG19) containing 23 markers spanning $39.6 \mathrm{cM}$. The LGs corresponded to the 19 chromosomes of B. napus including A1-A10 (A genome) and C1-C9 (C genome) as determined by shared SSR markers in
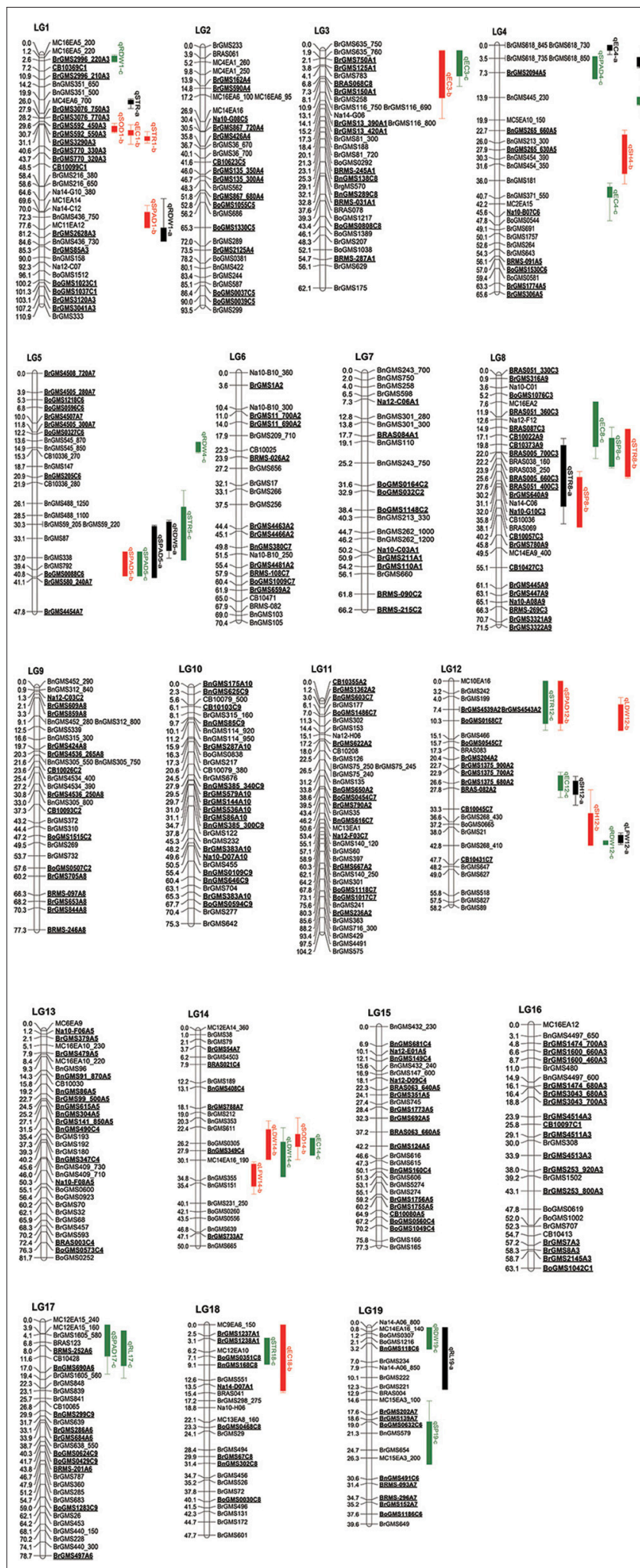

FIGURE 1 | Genetic map of $B$. napus with the locations of putative QTLs for salt tolerance based on $F_{2: 3}$ populations. The numbers of linkage groups are shown at the top, the genetic distance (CM) and markers are indicated at the left and right, respectively. The QTLs for ten indexes are signed on the right of linkage groups. 
TABLE 1 | Phenotypic performance of salt-tolerance traits in two parents and $F_{2: 3}$ population under $200 \mathrm{mM} \mathrm{NaCl}$.

\begin{tabular}{|c|c|c|c|c|c|c|c|c|}
\hline \multirow[t]{2}{*}{ Traits $^{a}$} & \multicolumn{2}{|c|}{ Parents $^{b}$} & \multicolumn{6}{|c|}{$F_{2: 3}$ Population $^{c}$} \\
\hline & 2205 & 1423 & Mean & Min & Max & SD & Skewness & Kurtosis \\
\hline STR & 0 & 3 & 0.74 & 0.00 & 2.00 & 0.429 & 0.505 & 0.338 \\
\hline SPAD & 31.80 & 24.60 & 33.05 & 27.50 & 39.07 & 2.895 & 0.025 & -0.307 \\
\hline EC & 0.48 & 0.95 & 0.69 & 0.49 & 0.91 & 0.13 & 0.047 & -0.631 \\
\hline$R L$ & 7.50 & 6.30 & 6.47 & 5.02 & 8.80 & 2.021 & 0.452 & -0.193 \\
\hline $\mathrm{SH}$ & 10.30 & 7.20 & 18.62 & 13.95 & 22.95 & 1.405 & -0.018 & -0.549 \\
\hline SP & 17.90 & 5.65 & 9.26 & 2.87 & 17.94 & 3.240 & 0.001 & -0.352 \\
\hline SOD & 30.00 & 15.00 & 26.70 & 13.95 & 45.72 & 6.870 & 0.345 & -0.192 \\
\hline LDW & 0.04 & 0.01 & 0.02 & 0.01 & 0.03 & 0.014 & 0.268 & 0.388 \\
\hline RDW & 0.05 & 0.02 & 0.05 & 0.02 & 0.09 & 0.015 & 0.499 & -0.137 \\
\hline LFW & 0.47 & 0.31 & 0.21 & 0.10 & 0.37 & 0.142 & 0.791 & 0.890 \\
\hline
\end{tabular}

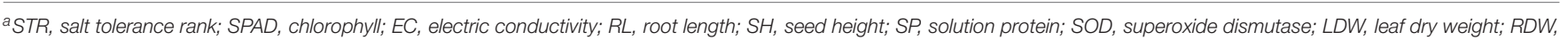
root dry weight; LFW, leaf fresh weight.

${ }^{b}$ Parents repeated in each sample measuring three times and presenting the mean value.

${ }^{c} F_{2: 3}$ population size $n=196$, replicates $r=3$.

TABLE 2 | Correlation coefficient between different indexes under $200 \mathrm{mM} \mathrm{NaCl}$.

\begin{tabular}{|c|c|c|c|c|c|c|c|c|c|}
\hline & SPAD & EC & $\mathbf{R L}$ & SH & SP & SOD & SDW & RDW & SFW \\
\hline STR & $-0.213^{\star \star}$ & $0.212^{\star *}$ & -0.062 & 0.044 & 0.08 & 0.178 & -0.029 & $-0.213^{*}$ & -0.196 \\
\hline SPAD & & $-0.329^{\star}$ & -0.026 & -0.041 & $0.219^{\star}$ & -0.149 & 0.199 & 0.125 & 0.068 \\
\hline EC & & & $-0.279^{*}$ & -0.107 & -0.089 & 0.028 & $-0.309^{\star}$ & $-0.276^{\star}$ & $-0.215^{\star}$ \\
\hline $\mathrm{RL}$ & & & & 0.041 & 0.028 & -0.183 & $0.598^{*}$ & 0.107 & $0.674^{*}$ \\
\hline $\mathrm{SH}$ & & & & & -0.106 & 0.005 & $0.302^{*}$ & 0.170 & 0.170 \\
\hline SDW & & & & & & & & $0.213^{*}$ & $0.815^{\star}$ \\
\hline RDW & & & & & & & & & 0.108 \\
\hline
\end{tabular}

${ }^{\star \star}$ and * Indicates significance at the level of 1 and 5\%, respectively.

public genetic maps (Cheng et al., 2009; Xu et al., 2010). A total of 131 SSR markers of the map were from the A genome, and 70 SSR markers were from the $\mathrm{C}$ genome. Because the $\mathrm{A}$ and $\mathrm{C}$ genomes share homology, partial linkage groups contain both the $\mathrm{A}$ and $\mathrm{C}$ genomic molecular markers, such as LG2, LG8, LG10, and so on (Table 3).

\section{QTL Mapping of Salt Tolerance at the Seedling Stage}

Forty-five QTLs controlling 10 traits were mapped on the linkage map (Table 4, Figure 1). Among them, seven QTLs associated with STR were detected on LG1, LG5, LG8, LG12, and LG18, respectively. Two QTLs (qSTR1-a and qSTR1-b) were detected in the same loci of LG1, and two QTLs (qSTR8-a and qSTR8-b) were identified in the same loci of LG8. All QTLs related to STR can explain more than $10 \%$ of the total phenotypic variance, and the QTL (qSTR18-c) on the LG18 accounted for 36.35\% of the total phenotypic variance. For SPAD, seven QTLs were mapped to five LGs. Three QTLs (qSPAD5-a, qSPAD5-b and qSPAD5 c) were located on the same loci of LG5 and showed relatively large effects on SPAD, accounting for 25.11, 37.49, and $51.14 \%$ of the total phenotypic variation, respectively. These QTLs had positive additive effects for increased SPAD from 2205. The other QTLs related to SPAD were detected on LG1, LG4, LG12, and LG17. For EC, seven QTLs were detected on LG1, LG3, LG4, LG8, LG12, LG14, and LG18. Among them, two QTLs (qEC3-a and qEC3b) were detected in the same region of LG3. qEC12-c located on the LG12 had the highest $r^{2}$ among all QTLs, accounting for $21.37 \%$ of the total phenotypic variation. All QTLs had positive additive effect for the increased EC. Five QTLs were identified for RDW, among which, qRDW1-a and qRDW4-c showed the largest effect on RDW, accounting for 23.56 and $18.9 \%$ of the total phenotypic variance, respectively. Only two QTLs (qSOD1$\mathrm{b}$ and qSOD14-b) for SOD were mapped to LG1 and LG14, respectively. They accounted for 19.7 and $27.5 \%$ of the total phenotypic variance and showed positive additive effect for the increased SOD. For SP, three QTLs were detected on LG8 (qSP8b and qSP8-c) and LG19 (qSP19-c), which accounted for 12.91, 8.9 , and $16.7 \%$ of the total phenotypic variance respectively. Three QTLs for SH were identified on LG4 and LG12, among which, qSH12-a and qSH12-b located on the LG12 were adjacent to each other. qSH4-b and qSH12-a, had the highest $r^{2}$ and 
TABLE 3 | Detailed information of genetic map constructed in the F2 population.

\begin{tabular}{|c|c|c|c|c|c|}
\hline $\begin{array}{l}\text { Linkage } \\
\text { groups }\end{array}$ & $\begin{array}{l}\text { Map length } \\
\text { (cM) }\end{array}$ & $\begin{array}{l}\text { No. of } \\
\text { loci }\end{array}$ & $\begin{array}{l}\text { No. of SSR } \\
\text { on A genome }\end{array}$ & $\begin{array}{l}\text { No. of SSR } \\
\text { C genome }\end{array}$ & $\begin{array}{l}\text { Map density } \\
\text { (cM/marker) }\end{array}$ \\
\hline 1 & 110.85 & 34 & $\mathrm{~A} 3 / 13$ & C1/4 & 3.26 \\
\hline 2 & 93.5 & 31 & $\mathrm{~A} 4 / 8$ & C5/6 & 3.01 \\
\hline 3 & 62.1 & 32 & $\mathrm{~A} 1 / 8$ & $\mathrm{C} 8 / 4$ & 1.94 \\
\hline 4 & 65.6 & 26 & A5/6 & $\mathrm{C} 6 / 2$ & 2.52 \\
\hline 5 & 47.8 & 23 & A7/7 & $\mathrm{C} 6 / 5$ & 2.08 \\
\hline 6 & 70.4 & 24 & $\mathrm{~A} 2 / 8$ & $\mathrm{C} 7 / 3$ & 2.93 \\
\hline 7 & 66.2 & 22 & $\mathrm{~A} 1 / 5$ & $\mathrm{C} 2 / 5$ & 3.01 \\
\hline 8 & 71.5 & 30 & A9/10 & C3/11 & 2.38 \\
\hline 9 & 77.3 & 30 & A8/10 & $\mathrm{C} 2 / 5$ & 2.58 \\
\hline 10 & 75.3 & 31 & A10/9 & $\mathrm{C} 9 / 8$ & 2.43 \\
\hline 11 & 104.2 & 37 & $\mathrm{~A} 2 / 5$ & $\mathrm{C} 7 / 2$ & 2.82 \\
\hline 12 & 58.2 & 25 & $\mathrm{~A} 2 / 5$ & $\mathrm{C} 7 / 2$ & 2.33 \\
\hline 13 & 81.7 & 32 & A5/9 & $\mathrm{C} 4 / 2$ & 2.55 \\
\hline 14 & 50.0 & 23 & $\mathrm{~A} 7 / 1$ & C4/1 & 2.17 \\
\hline 15 & 77.3 & 27 & A5/6 & C4/3 & 2.86 \\
\hline 16 & 63.1 & 26 & $\mathrm{~A} 3 / 11$ & C1/1 & 2.42 \\
\hline 17 & 78.7 & 31 & A6/4 & $\mathrm{C} 9 / 1$ & 2.54 \\
\hline 18 & 47.7 & 25 & $\mathrm{~A} 1 / 3$ & $\mathrm{C} 8 / 3$ & 1.91 \\
\hline 19 & 39.6 & 23 & A7/3 & $\mathrm{C} 6 / 2$ & 1.72 \\
\hline Total/mean & 1341.1 & 532 & 131 & 70 & 2.52 \\
\hline
\end{tabular}

accounted for 22.3 and $26.9 \%$ of the total phenotypic variance respectively. These two QTLs showed negative additive effect for the decreased SH. For RL, two QTLs (qRL17-c and qRL19a) were detected on LG17 and LG19, which accounted for 16.2 and $8.7 \%$ of the total phenotypic variance, respectively. These two QTLs showed positive additive effect for the increased RL. For LFW, three QTLs were mapped to LG4 (qLFW4-a), LG12 (qLFW12-a), and LG14 (qLFW14-b), which accounted for 24.3, 29.9 , and $16.54 \%$ of the total phenotypic variance, respectively. Two (qLF4-a and qLF14-b) showed positive additive effects for the increased LF and one (qLF12-a) showed negative additive effect for the decreased LF. Three QTLs for LDW were mapped to LG12 (qLDW12-b) and LG14 (qLDW14-b and qLDW14c) respectively, which accounted for $12.1,14.2$, and $20.74 \%$ of the total phenotypic variance, respectively. By comparing the QTLs of different indexes, it was found that many QTLs from different indexes were mapped to the same region of the linkage group (Figure 1). The QTLs, qSTR1-a, qSTR1-b, qSOD1-b, and qEC1-b, were mapped to the same region of LG1. qSPAD1-b and qRDW1-a were detected in another region of LG1. Three QTLs, qSPAD4-c, qEC4-a, and qLFW4-a were mapped to the same area of LG4. Three QTLs (qSPAD5-a, qSPAD5-b, and qSPAD5-c) for SPAD, one QTL for STR (q STR5-c) and one QTL for RDW (qRDW5-a) were detected in the same region of LG5. Two QTLs (qSTR8-a and qSTR8-b) for STR, two QTLs (qSP8-b and qSP8-c) for SP and one QTL (qEC8-c) for EC were also clustered to the similar area of LG8. Five QTLs for four indexes were also identified in the same area of LG14 (Figure 1).

\section{Fine Mapping of the Salt Tolerance Gene on LG5}

As three QTLs related to SPAD on the LG5 were detected in the same area, it was speculated that they are the same loci, which means the same QTL can be detected in three replicates. Therefore, the sequences of the markers on either sides of the QTL (BrGMS338, BrGMS792 and BrGMS580_240) were analyzed. The result showed that the QTL was located between 16.33 and $23.14 \mathrm{Mb}$ on $\mathrm{A} 07$ of $B$. rapa. In order to narrow down the region of the QTL, 20 gene sequences within this region were selected to design IP primers. Two IP primers, IP05 and IP08 were successfully designed to amplify the polymorphic bands between the two parents and $\mathrm{F}_{2}$ populations. Win QTL Cartographer v.2.5 was used to analyze the phenotypes and polymorphic bands. The interval of the QTL was finally mapped to a interval between IP05 (17.41 Mb) and BrGMS792 (17.80 Mb) with a region of $390 \mathrm{~Kb}$ (Table 5, Figure 2). A total of 66 genes were identified in this region by comparing the database (http:// brassicadb.org/brad/). By analyzing the functional annotation of each gene in this region, one gene, Bra003640, was found to be associated with salt tolerance in plants. Thus, Bra003640 was further investigated as a candidate gene for this study.

\section{Structural Analysis of the Salt Tolerant Candidate Gene}

The candidate gene was amplified in the two parents 2205 and 1423 by homologous cloning according to the sequence of Bra003640. These two genes were named as Bn2205 and $B n 1423$, respectively. The full-length of the genes in both 2205 and 1423 were $1,063 \mathrm{bp}$, which contained three exons and two introns. The ORFs were $867 \mathrm{bp}$ encoding a protein of 287 amino acids, with the isoelectric points of 5.99 and 6.04 , and the molecular weights of 31.34 and $31.30 \mathrm{kDa}$, respectively. The ORF sequences of $B n 2205$ and $B n 1423$ were compared by the DNAMAN5.0 software. The results showed there were 11 single nucleotide differences between them, resulting in seven amino acid changes (34, 54, 83, 174, 212, 257, and 272) (Table 6, Figure 3). Two typical B-box zinc finger protein domains were found between residues 4-46 and 52-99, respectively, by comparing the conserved domain database (Figure 3). Among them, the amino acids 57-90 are typical C2C2 and C2H2 type zinc fingers. Three amino acid changes (34, 54, and 83) were identified in the conserved domain between the two parents. The amino acid sequences of the two genes were aligned to those from the Arabidopsis thaliana database (http://www.Arabidopsis. Org/), which showed the closest homologous was Arabidopsis BBX22.

The BLAST tool developed by NCBI was used to search for the B-box zinc finger proteins in Brassica species reported in GenBank and the phylogenetic analysis was conducted. The results showed that Bra003640 from B. rapa, Bol021552 from B. oleracea, and GSBRNA2T00084211001 and GSBRNA2T00131912001 from B. napus were clustered together with Bn2205 and Bn1423 (Figure 4). All above genes had the function of salt stress induction. Therefore, it is presumed that the candidate gene can respond to salt stress. A sequence of 1,500 
TABLE 4 | Detailed information of QTLs for relevant indexes.

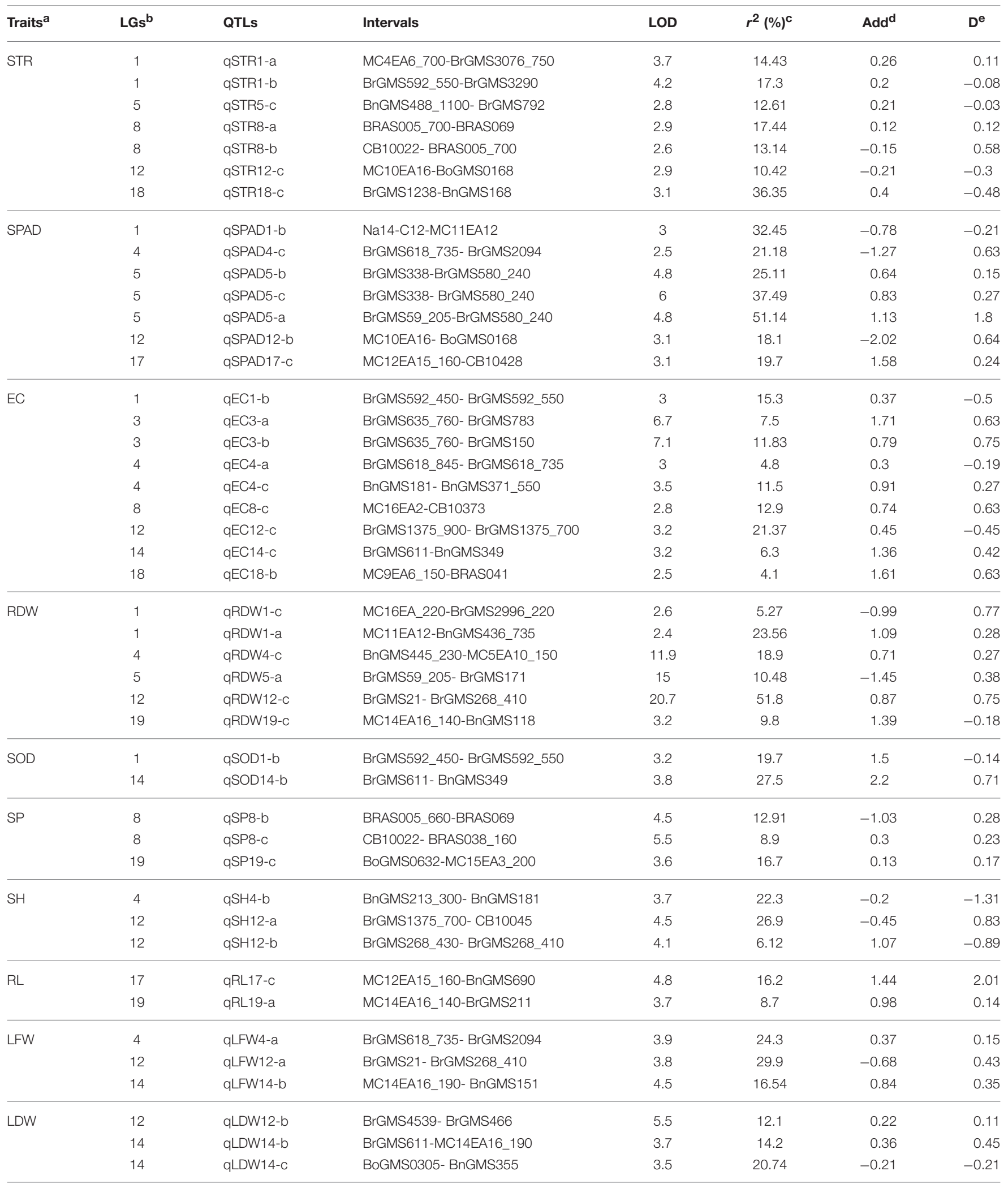

Traits: ten salt tolerance indicators;

b LGs: linkage groups on which the QTL was located;

$c r^{2}$ : Variation accounted for by each putative $Q T L$;

${ }^{d}$ Add: Additive effect.

${ }^{e} D$ : Dominant effect. 
bp upstream of the ATG of Bn2205 and Bn1423 was analyzed for cis-acting elements using Plant CARE. Table 7 showed that a number of cis-acting elements AF1, HD-Zip 1, LTR, and HSE are related to plant stress tolerance and transcriptional activity, suggesting that the Bra003640 gene may be induced by abiotic stresses.

\section{Expression of the Salt Tolerant Candidate Gene}

The RT-qPCR technique was used to analyze the expression of the candidate gene under the high salt treatment. The results showed

TABLE 5 | Information of molecular markers linked to qSPAD5.

\begin{tabular}{|c|c|c|}
\hline Markers & Sequences $\left(5^{\prime}-3^{\prime}\right)$ & Location (Mb) \\
\hline BrGMS338 & $\begin{array}{l}\text { CTAGGGAGAGAGAACAACTCGC/ } \\
\text { GTGCTCAAAGATACACGTTCG }\end{array}$ & 16.337 \\
\hline BrGMS792 & $\begin{array}{l}\text { САTTGTCCCCATCTCTTACCAT/ } \\
\text { GAAGGAGGTGAGTITGAGCTTG }\end{array}$ & 17.874 \\
\hline BrGMS580_240 & $\begin{array}{l}\text { ATATCGAGCGGTACGGAGATTA } \\
\text { CGATITCTAGGGTTCTTCCTCC }\end{array}$ & 23.140 \\
\hline IP05 & $\begin{array}{l}\text { TAACACTTGCATTCGCGGTG/ } \\
\text { GGTCCATAGTCACCATCTCCG }\end{array}$ & 17.410 \\
\hline IP08 & $\begin{array}{l}\text { ССTCTGCПTCTICGCATCA } \\
\text { GGCGTGAGTCAGAGGAAGAC }\end{array}$ & 17.602 \\
\hline
\end{tabular}

that the expression of this gene was low without salt stress, but increased under high salt stress between the two parents. We had observed differential expression of the candidate gene in leaf and root samples between parents. In the leaves, the candidate gene was significant highly expressed in 1423 compared to 2205 at $6 \mathrm{~h}$ under 100 and $200 \mathrm{mM} \mathrm{NaCl}$ treatment (Figure 5). In the roots, comparing with 2205 , the candidate gene was significant highly expressed in 1423 at $6 \mathrm{~h}$ under $100 \mathrm{mM}$ whereas $24 \mathrm{~h}$ under $200 \mathrm{mM} \mathrm{NaCl}$. The expression in both parents showed a downward trend with time, however, a drastic increase in expression was observed in 1423 at the $24 \mathrm{~h}$ under $200 \mathrm{mM} \mathrm{NaCl}$ (Figure 6). Therefore, our results show that the candidate gene is associated with salt stress.

\section{DISCUSSION}

Salinization of land is one of the crises the world is facing today; therefore, it is urgent to plant crops on the saline-alkali

TABLE 6 | Structure analysis of Bn2205 and Bn1423.

\begin{tabular}{llllllll}
\hline Lene & Loci & $\mathbf{5 4}$ & $\mathbf{8 3}$ & $\mathbf{1 7 4}$ & $\mathbf{2 1 2}$ & $\mathbf{2 5 7}$ & $\mathbf{2 7 2}$ \\
\hline Bn2205 (Amino acids) & $\mathrm{T}$ & $\mathrm{I}$ & $\mathrm{A}$ & $\mathrm{S}$ & $\mathrm{S}$ & $\mathrm{F}$ & $\mathrm{H}$ \\
Bn1423 (Amino acids) & $\mathrm{A}$ & $\mathrm{K}$ & $\mathrm{S}$ & $\mathrm{P}$ & $\mathrm{N}$ & $\mathrm{S}$ & $\mathrm{L}$
\end{tabular}

\section{LG5}
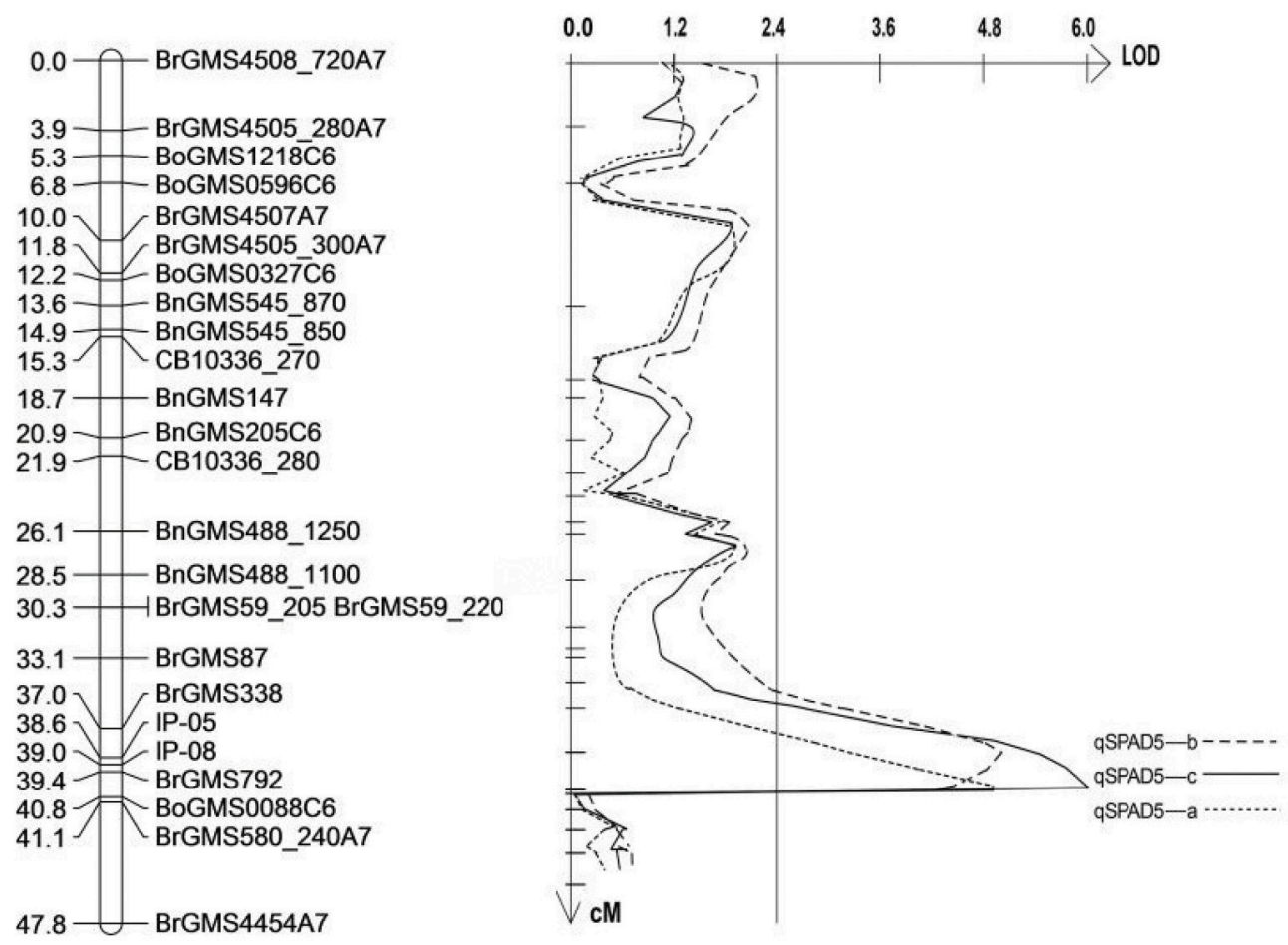

FIGURE 2 | Mapping of QTLs related to salt tolerance on LG5. The markers names are shown to the right of the linkage group (LG5), and genetic distance (cM) is on the left. The vertical line is LOD threshold for QTL. 


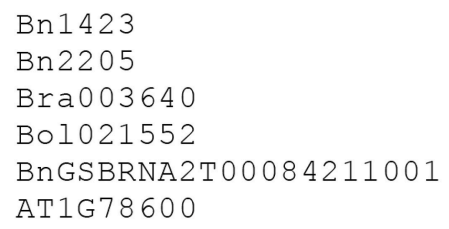

Bn 1423

Bn 2205

Bra003640

Bol021552

BnGSBRNA2T00084211001 AT1G78600

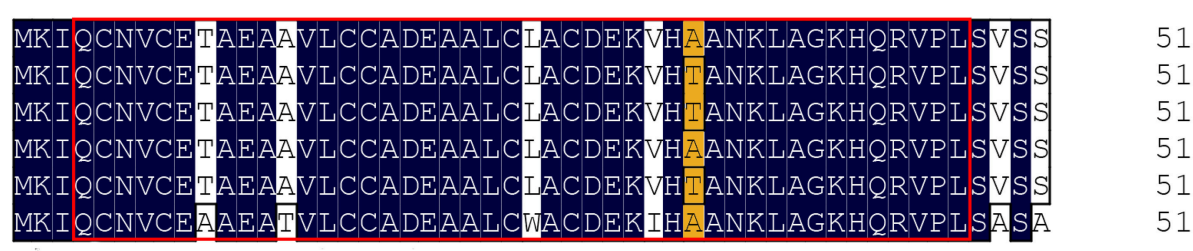

\section{$\mathrm{B}-\mathrm{BOX}$}

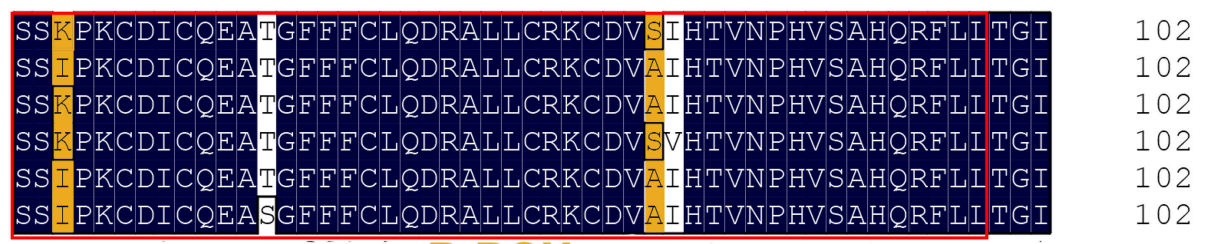

\section{B-BOX}

Bn 1423

Bn 2205

Bra003640

Bol021552

BnGSBRNA2T00084211001 AT1G78600

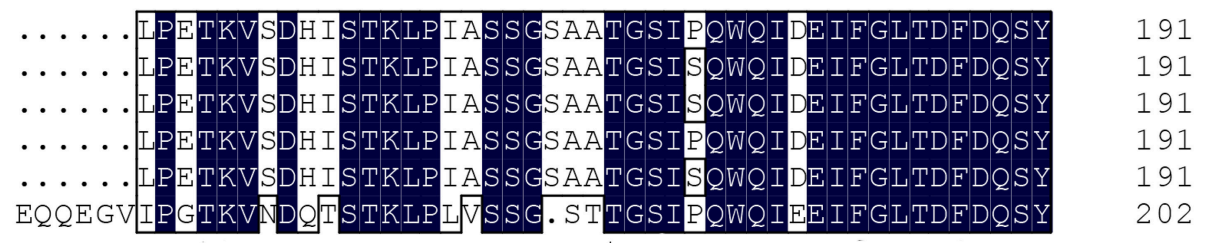

191

191

191

91

202

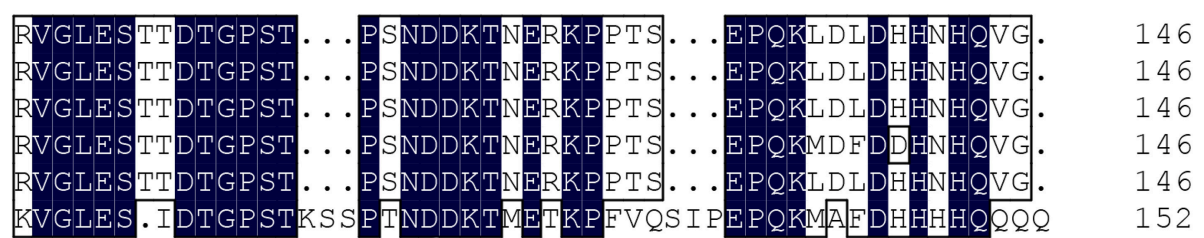

242

242

242

242

242

252

288

288

288

288

288

299

FIGURE 3 | Sequences comparison of Bra003640 between Arabidopsis and Brassica species. The red rectangle indicates the two B-box zinc finger protein domains. The mutant amino acids between the two parents in B-box zinc finger protein domains are indicated in yellow, the other mutant amino acids are indicated in white.

soil to meet human needs. At present, studies of salt tolerance are mainly focused on rice, wheat, cucumber and other crops (Lindsay et al., 2004; Huang et al., 2006; Wang et al., 2012; Ghomi et al., 2013; Song et al., 2016). However, little has been done on salt tolerance of rapeseed. Salt resistance of crops is complex due to interacting factors, some of which are only activated in salt stress. Thus, it is difficult to evaluate these factors under normal growth conditions. An effective way to evaluate salt resistance is by using the physiological and morphological indexes of plants under salt stress. In this study, a number of physiological and morphological indicators were used to determine the salt tolerance of B. napus, and some major QTLs related to salt tolerance were obtained. Some of them accounted for more than $20 \%$ of the phenotypic variance, such as qSPAD5-a, 


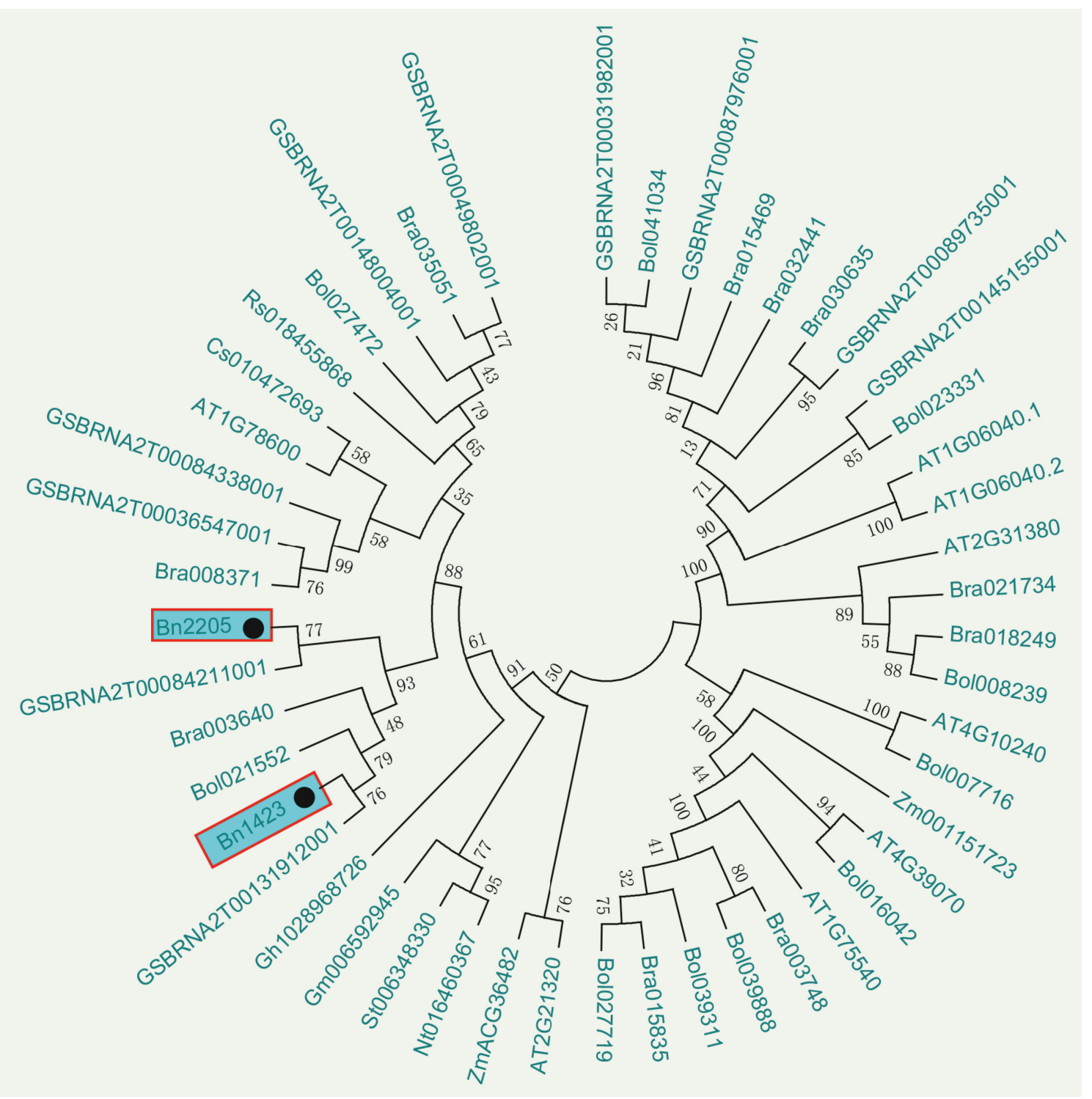

FIGURE 4 | Phylogenetic tree analysis of the candidate genes. Numbers are bootstrap values indicating frequencies of respective furcations found in 1,000 replications of subset tree calculations.

TABLE 7 | Analysis of cis-acting elements in the upstream of the candidate gene.

\begin{tabular}{lll}
\hline Cis-acting elements & Core sequence & Annotation \\
\hline 3-AF1 binding site & AAGAGATATTT & Light responsive element \\
Box I & TTCAAA & Light responsive element \\
CAT-box & GCCACT & Meristem expressionelement \\
HD-Zip 1 & CAAT(A/T)ATTG & $\begin{array}{l}\text { Palisade mesophyll cells } \\
\text { Control of leaf morphology } \\
\text { HD-Zip 2 }\end{array}$ \\
CAAT(G/C)ATTG & development \\
HSE & AAAAAATTC & $\begin{array}{l}\text { Heat stress } \\
\text { responsivenesselement } \\
\text { Low-temperature }\end{array}$ \\
LTR & CCGAAA & $\begin{array}{l}\text { responsivenesselement } \\
\end{array}$
\end{tabular}

qSPAD5-b, qSPAD5-c, qSTR18-c and so on. Many QTLs for different indicators were mapped to the same region, such as the QTLs on LG1, LG4, LG5, LG8, and LG14. Our results suggest the salt-related QTLs we mapped are accurate and the presence of a single gene in this region controls multiple traits. Multiple indicators were used to analyze salt tolerance. Many salt tolerance-related QTLs were mapped to the same region, which provides a very reliable reference for the selection of salt-tolerant candidates in further studies.

Currently, only a few reports about the genetics of salt tolerance in rapeseed were published, and not too many genes have been mapped or cloned. Map-based cloning has long been considered as a reliable and effective means of gene cloning, 


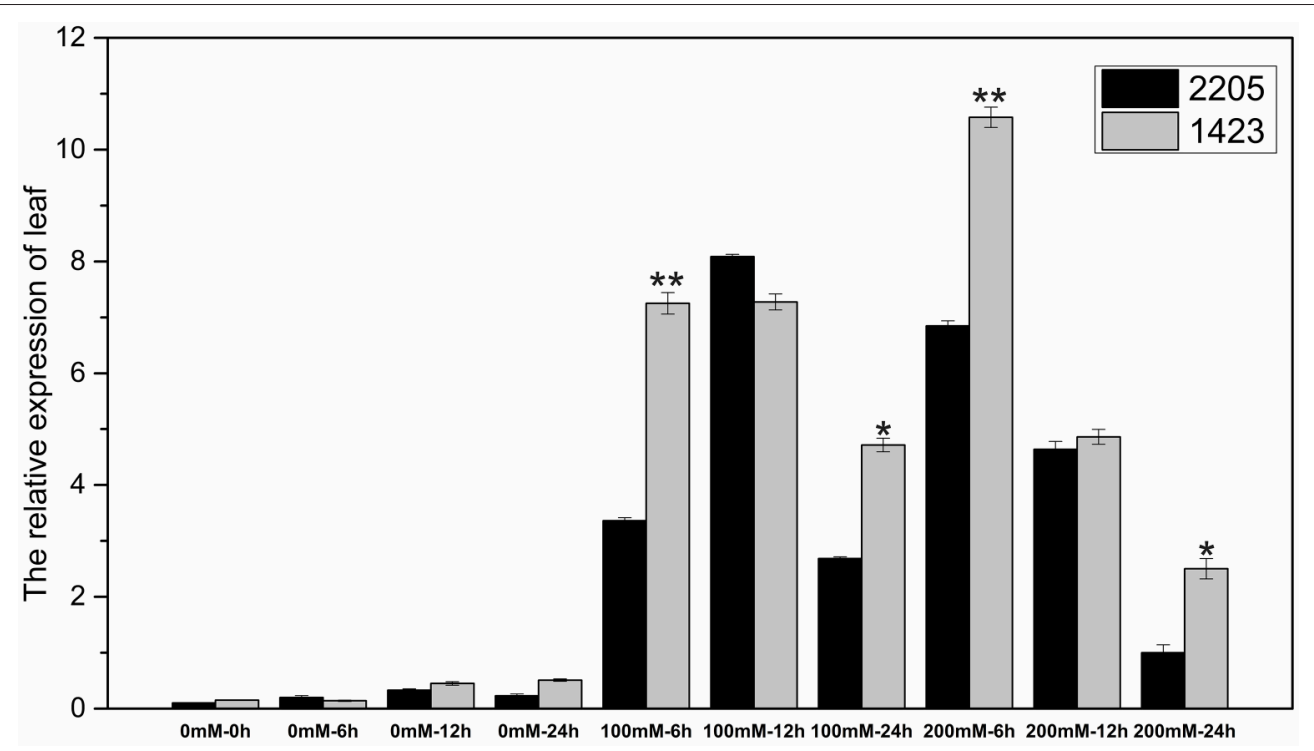

FIGURE 5 | Expression of the candidate gene in leaves of the two parents. * and ${ }^{\star \star}$ stand for significance level at $P<0.05$ and $P<0.01$, respectively.

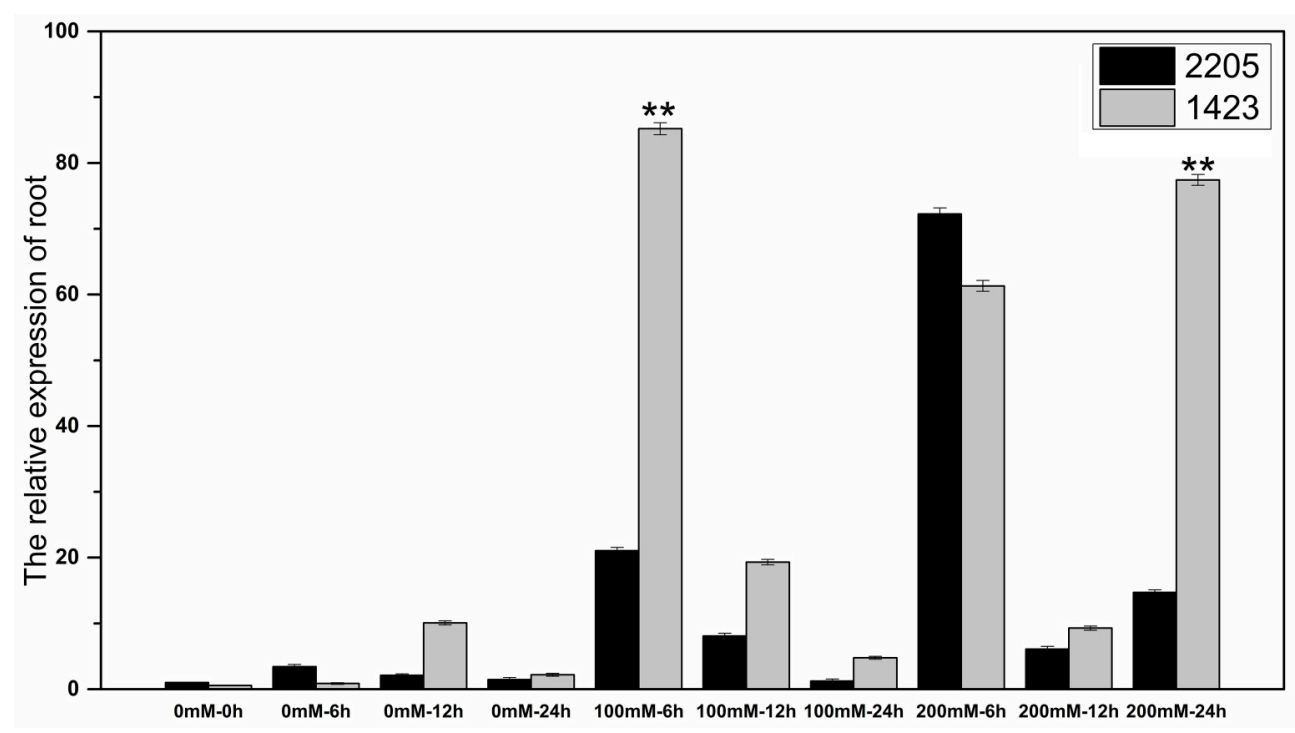

FIGURE 6 | Expression of the candidate gene in roots of the two parents. ${ }^{* *}$ stands for significance level at $P<0.01$.

and many genes have been cloned in Brassica using this method (Dun et al., 2011; Li et al., 2012). In this study, the map-based cloning technology was used to map and clone the salt tolerance related genes. A key step is the identification of candidate genes for salt tolerance, and this work is premised on fine mapping of salt-tolerant genes. Therefore, The QTL technology was used to identify the QTLs related with salt tolerance. The salt tolerance of rapeseed was indirectly measured by several indexes. Our results show a number of major QTLs related with salt tolerance were detected, and some of the QTLs were enriched in a specific region of the linkage group. Thus, these areas were identified as the candidate regions of salt-tolerant related genes. In this study, the QTL associated with SPAD on LG5 could be detected repeatedly in the same region, and several QTLs for other traits were also mapped to this region, therefore, there is a high probability of salt tolerance genes located in this region. However, the QTL region (qSPAD5-a, qSPAD5-b, qSPAD5-c) has $6.8 \mathrm{Mb}$ in the initial QTL mapping, and there are hundreds of genes in this region, it is difficult to screen the genes related to salt tolerance. Fortunately, the sequence of the Chinese cabbage genome has been published, and some genes have very detailed functional annotations, which facilitate us to exploit the sequence of the genes in the QTL region 
to develop closer molecular markers. Two salt-related IP markers were developed to narrow down the QTL region to $390 \mathrm{~kb}$. In fact, a similar approach has been used to fine map the target genes in previous studies (Huang et al., 2016). A total of 66 genes were identified in this region by analyzing the functional annotations of these genes. Bra003640, associated with salt tolerance, was identified for subsequent studies. Through gene structure and expression analysis, it was found that the gene sequence between the two parents was different, particularly the presence of three different amino acids within the conserved domain. We further verified its function by the transgenic technology. Additionally, for LG1, LG4 and other QTL enrichment intervals, a similar method was used to develop IP markers to narrow down the QTL interval. Meanwhile, in order to finely map the genes related to salt tolerance in these QTLs regions, an $\mathrm{F}_{2: 3}$ population of 1,200 lines was constructed, and the phenotypic identification is ongoing in our lab.

As the salt tolerance of rapeseed was measured by various morphological and physiological indicators under salt stress, this work was complicated and time consuming, which need a long time and a large space and bring great difficulties to salt-tolerant breeding of rapeseed. With the development of molecular biology, molecular breeding technology is increasingly used in rapeseed germplasm innovation and improvement. In this study, many QTLs related to salt tolerance were identified, and a number of molecular markers linked to these major QTLs

\section{REFERENCES}

Ahmadi, J., and Fotokian, M. H. (2011). Identification and mapping of quantitative trait loci associated with salinity tolerance in rice (Oryzasativa) using SSR markers. Iran. J. Biotechnol. 9, 21-30.

Basten, C. J., Weir, B. S., and Zeng, Z. (1997). QTL Cartographer: A Reference Manual and Tutorial for QTL Mapping. Raleigh, NC: North Carolina State University.

Beauchamp, C., and Fridovich, I. (1971). Superoxide dismutase: improved assays and an assay applicable to acrylamide gels. Anal. Biochem. 44, 276-287. doi: 10.1016/0003-2697(71)90370-8

Chakraborty, K., Sairam, R. K., and Bhattacharya, R. C. (2012). Differential expression of salt overly sensitive pathway genes determines salinity stress tolerance in Brassica genotypes. Plant Physiol. Biochem. 51, 90-101. doi: 10.1016/j.plaphy.2011.10.001

Cheng, X., Xu, J., Xia, S., Gu, J., Yang, Y., Fu, J., et al. (2009). Development and genetic mapping of microsatellite markers from genome survey sequences in Brassica napus. Theor. Appl. Genet. 118, 1121-1131. doi: 10.1007/s00122-009-0967-8

Ding, J., Huang, Z., Zhang, X., Lu, H., Liu, L., and Xu, A. (2014). Physiological effects on Brassica napus seedlings under $\mathrm{NaCl}$ stress. Acta Bot. Boreal. 34, 2270-2276. doi: 10.7606/j.issn.1000-4025.2014.11.2270

Doyle, J. J., and Doyle, J. L. (1990). Isolation of plant DNA from fresh tissue. Focus $12,13-15$.

Du, K., Gao, Y., Kong, Y., Fan, Y., and Wang, Y. (2013). Effects of OsLTP gene on salt tolerance of transgenic Brassica napus. Sci. Agric. Sin. 46, 2625-2632. doi: 10.3864/j.issn.0578-1752.2013.13.001

Dubcovsky, J., Maria, G. S., Epstein, E., Luo, M. C., and Dvorak, J. (1996). Mapping of the $\mathrm{K}^{+} / \mathrm{Na}^{+}$discrimination locus Knal in wheat. Theor. Appl. Genet. 92, 448-454. doi: 10.1007/BF00223692

Dun, X., Zhou, Z., Xia, S., Wen, J., Yi, B., Shen, J., et al. (2011). BnaC.Tic40, a plastid inner membrane translocon originating from Brassica oleracea, is essential for were obtained, such as SSR and IP markers associated with SPAD. These markers can be used to screen salt tolerant germplasm of rapeseed and cultivate salt-tolerant rapeseed. The utilization of these molecular markers combined with comprehensive trait observation will not only save time and space for breeders, but also the accuracy of selection will be increased substantially.

\section{AUTHORS CONTRIBUTIONS}

$\mathrm{ZH}$ was responsible for designing this study and drafting the manuscript; LL and JuD carried out the QTL mapping of salt tolerance; AX carried out gene cloning and expression; YZ, ZT, YL, and NZ carried out the data analysis and manuscript preparation; YW, XL, FL, BZ, MQ, and JaD collected important background information and provided assistance for data acquisition, data analysis and statistical analysis. All authors have read and approved the content of the manuscript.

\section{ACKNOWLEDGMENTS}

The research was supported by National Natural Science Foundation of China (31301350), the National key research and development program (2016YFD0101300; 2016YFD0100202), Zhongying Youth Scholar Program of Northwest A\&F University and Shaanxi Science and Technology Innovation Program (2016KTCQ02-03).

tapetal function and microspore development in Brassica napus. Plant J. 68, 532-545. doi: 10.1111/j.1365-313X.2011.04708.x

Fan, C., Cai, G., Qin, J., Li, Q., Yang, M., Wu, J., et al. (2010). Mapping of quantitative trait loci and development of allele-specific markers for seed weight in Brassica napus. Theor. Appl. Genet. 121, 1289-1301. doi: 10.1007/s00122-010-1388-4

Ghomi, K., Rabiei, B., Sabouri, H., and Sabouri, A. (2013). Mapping QTLs for traits related to salinity tolerance at seedling stage of rice (Oryza sativa L.): an agrigenomics study of an Iranian rice population. Omi. J. Integr. Biol. 17, 242-251. doi: 10.1089/omi.2012.0097

Gorham, J., Jones, R. G. W., and Bristol, A. (1990). Partial characterization of the trait for enhanced $\mathrm{K}+-\mathrm{Na}+$ discrimination in the $\mathrm{D}$ genome of wheat. Planta 180, 590-597. doi: 10.1007/BF02411458

Guo, G., Du, Y., Shi, Q., Zhou, X., Ma, D., Wang, H., et al. (2013). Impacts of salt stress on growth and physiological characteristics of Cerasus humilises. Xinjiang Agric. Sci. 50, 471-475. doi: 10.6048/j.issn.1001-4330.2013.03.013

Huang, S., Spielmeyer, W., Lagudah, E. S., James, R. A., Platten, J. D., Dennis, E. S., et al. (2006). A sodium transporter (HKT7) is a candidate for Nax1, a gene for salt tolerance in durum Wheat. Plant Physiol. 142, 1718-1727. doi: 10.1104/pp.106.088864

Huang, Z., Chen, Y., Yi, B., Xiao, L., Ma, C., Tu, J., et al. (2007). Fine mapping of the recessive genic male sterility gene (Bnms3) in Brassica napus L. Theor. Appl. Genet. 115, 113-118. doi: 10.1007/s00122-007-0547-8

Huang, Z., Liu, L., Lu, H., Lang, L., Zhao, N., Ding, J., et al. (2016). Development of IP and SCAR markers linked to the yellow seed color gene in Brassica juncea L. Breed. Sci. 66, 175-180. doi: 10.1270/jsbbs.66.175

Huang, Z., Yang, R., Xu, A., Li, J., Lu, R., and Luo, P. (2010). Effects of saline stress on seed germination and seedlings properties of three types of rapeseed. J. Northw. A\&F Univ. 48, 49-53. doi: 10.13207/j.cnki.jnwafu.2010.07.012

Im, C. H., Kim, M., Kim, K., Cho, S. J., Lee, J. J., Joung, W., et al. (2014). Breeding of Pleurotus eryngii with a high temperature tolerance trait. J. Mushrooms 12, 187-192. doi: 10.4489/KJM.2013.41.2.91 
Jain, R. K., Jain, S., Nainawatee, H. S., and Chowdhuryt, J. B. (1990). Salt-tolerance in Brassica juncea L. I. In vitro selection, agronomic evaluation and genetic stability. Euphytica 48, 141-152. doi: 10.1007/BF00037193

Kaya, C., Higgs, D., and Sakar, E. (2002). Response of two leafy vegetables growth at high salinity to supplementary potassium and phosphorus during different growth stages. J. Plant Nutr. 25, 2663-2676. doi: 10.1081/PLN-120005399

Kosambi, D. D. (1944). The estimation of map distances from recombination values. Ann. Eugen. 12, 172-175. doi: 10.1111/j.1469-1809.1943.tb02321.x

Kumar, M., Kim, S. R., Sharma P. C., and Chander A. (2015). Simple and efficient way to detect small polymorphic bands in plants. Genomics Data 5, 218-222. doi: 10.1016/j.gdata.2015.06.006

Lander, E. S., Green, P., Abrahamson, J., Barlow, A., Daly, M. J., Lincoln, S. E., et al. (1987). Mapmaker: an interactive computer package for constructing primary genetic linkage maps of experimental and natural populations. Genomics 1, 174-181. doi: 10.1016/0888-7543(87)90010-3

Li, H. (2000). The Experiment Principle and the Technology of Plant Physiology. Beijing: Higher Education Press.

Li, X., Chen, L., Hong, M., Zhang, Y., Zu, F., Wen, J., et al. (2012). A large insertion in $b H L H$ transcription factor BrTT8 resulting in yellow seed coat in Brassica rapa. PLoS ONE 7:e44145. doi: 10.1371/journal.pone.0044145

Li, Z., and Zhang, W. (2013). Growth and physiological response of Quercus variabilis seedlings under $\mathrm{NaCl}$ stress. Acta Bot. 33, 1630-1637.

Lincoln, S. E., Daly, M. J., and Lander, E. S. (1992). Constructing Genetic Maps with MapMaker/EXP3.0, 3rd Edn. Whitehead Inst. Tech. Rep.

Lindsay, M. P., Lagudah, E. S., Hare, R. A., and Munns, R. (2004). A locus for sodium exclusion (Naxl), a trait for salt tolerance, mapped in durum wheat. Funct. Plant Biol. 31, 1105-1114. doi: 10.1071/FP04111

Lowe, A. J., Moule, C., Trick, M., and Edwards, K. J. (2004). Efficient large-scale development of microsatellites for marker and mapping applications in Brassica crop species. Theor. Appl. Genet. 108, 1103-1112. doi: $10.1007 /$ s00122-003-1522-7

Lu, G., Yang, G., and Fu, T. (2001). Silver-stained aflp-a novel assay for DNA fingerprinting in Brassica napus. J. Huazhong Agric. Univ. 20, 413-415. doi: 10.13300/j.cnki.hnlkxb.2001.05.002

Ma, J., Zhang, H., Zhao, Z., and Zhang, C. (2001). Progress in mechanisms of plant resistance to salt stress. Life Sci. Res. 5, 175-179. doi: 10.3969/j.issn.1007-7847.2001.z1.037

Munns, R. (2002). Comparative physiology of salt and water stress. Plant Cell Environ. 25, 239-250. doi: 10.1046/j.0016-8025.2001.00808.x

Nguyen, T., Friedt, W., and Snowdon, R. (2007). "Cloning and mapping of a candidate gene for germination and seedling vigour in yellow-seeded oilseed rape," in The 12th International Rapeseed Congress, ed T. D. Fu (Wuhan), 4.

Peng, Y., Zhu, Y., Mao, Y., Wang, S., Su, W., and Tang, Z. (2004). Alkali grass resists salt stress through high $\left[\mathrm{K}^{+}\right]$and an endodermis barrier to $\mathrm{Na}^{+}$. J. Exp. Bot. 55, 939-949. doi: 10.1093/jxb/erh071

Piquemal, J., Cinquin, E., Couton, F., Rondeau, C., Seignoret, E., Doucet, I., et al. (2005). Construction of an oilseed rape (Brassica napus L.) genetic map with SSR markers. Theor. Appl. Genet. 111, 1514-1523. doi: 10.1007/s00122-005-0080-6

Ren, Z., Zheng, Z., Chinnusamy, V., Zhu, J., Cui, X., Iida, K., et al. (2010). RAS1, a quantitative trait locus for salt tolerance and ABA sensitivity in Arabidopsis. Proc. Natl. Acad. Sci. U.S.A. 107, 5669-5674. doi: 10.1073/pnas.0910798107

Sabouri, H., and Sabouri, A. (2008). New evidence of QTLs attributed to salinity tolerance in rice. Afr. J. Biotechnol. 7, 4376-4383. doi: 10.1007/s11033-013-2561-Z

Song, Z., Miao, H., Zhang, S., Wang, Y., Zhang, S., and Gu, X. (2016). Genetic analysis and QTL mapping of fruit peduncle length in Cucumber
(Cucumis sativus L.). PLoS ONE 11:e0167845. doi: 10.1371/journal.pone. 0167845

Su, J., Wu, S., Xu, Z., Qiu, S., Luo, T., Yang, Y., et al. (2013). Comparison of salt tolerance in Brassicas and some related species. Am. J. Plant Sci. 4, 1911-1917. doi: 10.4236/ajps.2013.410234

Thakur, M., and Sharma, A. D. (2005). Salt-stress-induced proline accumulation in germinating embryos: evidence suggesting a role of proline in seed germination. J. Arid Environ. 62, 517-523. doi: 10.1016/j.jaridenv.2005.01.005

Vos, P., Hogers, R., Bleeker, M., Reijans, M., Vandelee, T., Hornes, M., et al. (1995). AFLP:a new technique for DNA-fingerprinting. Nucleic Acids Res. 23, 4407-4414. doi: 10.1093/nar/23.21.4407

Wang, S., Li, J., Guo, S., Hu, X., Li, J., and Wang, T. (2006). Effects of $\mathrm{NaCl}$ stress on growth and photosynthetic characteristics of Cucumber (Cucumber sativus L.) seedlings. Acta Bot. Boreal. 26, 455-461. doi: 10.3321/j.issn:1000-4025.2006.03.004

Wang, Z., Chen, Z., Cheng, J., Lai, Y., Wang, J., Bao, Y., et al. (2012). QTL analysis of $\mathrm{Na}^{+}$and $\mathrm{K}^{+}$concentrations in roots and shoots under different levels of $\mathrm{NaCl}$ stress in rice (Oryza sativa L.). PLoS ONE 7:e51202. doi: 10.1371/journal.pone.0051202

Wani, A. S., Aqil, A., Shamsul, H., and Qazi, F. (2013). Salt-induced modulation in growth, photosynthesis and antioxidant system in two varieties of Brassica juncea. Saudi J. Biol. Sci. 20, 183-193. doi: 10.1016/j.sjbs.2013. 01.006

Xu, J., Qian, X., Wang, X., Li, R., Cheng, X., Yang, Y., et al. (2010). Construction of an integrated genetic linkage map for the A genome of Brassica napus using SSR markers derived from sequenced BACs in B. rapa. BMC Genomics 11:594. doi: 10.1186/1471-2164-11-594

Yang, S., Zhang, H., and Zhang, L. (2010). Physiological and biochemical indices of salt tolerance and scanning of salt-tolerance plants:a review. J. Northwest For. Univ. 25, 59-65.

Yao, M., Wang, J., Chen, H., Zhai, H., and Zhang, H. (2005). Inheritance and QTL mapping of salt tolerance in rice. Rice Sci. 12, 25-32.

Yeo, A. R., and Flowers, T. J. (1986). Salinity resistance in rice (Oryza sativa L.) and a pyramiding approach to breeding varieties for saline soils. J. Plant Physiol. 13, 161-173. doi: 10.1071/PP9860161

Yin, Y., Wang, H., and Liao, X. (2009). Analysis and strategy for 2009 rapeseed industry development in China. Chin. J. Oil Crop Sci. 31, 259-262.

Zhang, F., Ding, J., Tashpolat, T., and Wang, B. (2007). Analysis on characteristics of soil salinization in the arid regions: a case study in the delta oasis of Weigan and Kuqa rivers. Acta Prataculturae Sin. 16, 34-40.

Zhang, T. (2012). Effects of $\mathrm{NaCl}$ stress on several physiological and biochemical characteristics of Rape seedlings. North. Hortic. 16, 16-18.

Zheng, Q., Liu, H., Long, X., Liu, Z., Niu, D., and Gao, Y. (2010). Effects of salt stress on ionic absorption and distribution of rapeseed seedlings. Chin. J. Oil Crop Sci. 32, 65-70.

Conflict of Interest Statement: The authors declare that the research was conducted in the absence of any commercial or financial relationships that could be construed as a potential conflict of interest.

Copyright (c) 2017 Lang, Xu, Ding, Zhang, Zhao, Tian, Liu, Wang, Liu, Liang, Zhang, Qin, Dalelhan and Huang. This is an open-access article distributed under the terms of the Creative Commons Attribution License (CC BY). The use, distribution or reproduction in other forums is permitted, provided the original author(s) or licensor are credited and that the original publication in this journal is cited, in accordance with accepted academic practice. No use, distribution or reproduction is permitted which does not comply with these terms. 